Article

\title{
Developing On-Road NOx Emission Factors for Euro 6b Light-Duty Diesel Trucks in Korean Driving Conditions
}

\author{
Seungcheon Ro, Junhong Park *, Myunghwan Shin and Jongtae Lee \\ National Institute of Environmental Research (NIER), 42 Hwangyeong Road, Seo, Incheon 22689, Korea; \\ rosc88@korea.kr (S.R.); smh@korea.kr (M.S.); leelee@korea.kr (J.L.) \\ * Correspondence: pjhy98@korea.kr; Tel.:+82-32-560-7625
}

Citation: Ro, S.; Park, J.; Shin, M.; Lee, J. Developing On-Road NOx Emission Factors for Euro $6 \mathrm{~b}$ Light-Duty Diesel Trucks in Korean Driving Conditions. Energies 2021, 14 1041. https://doi.org/10.3390/en14 041041

Academic Editor: Roger Gläser

Received: 30 December 2020

Accepted: 12 February 2021

Published: 16 February 2021

Publisher's Note: MDPI stays neutral with regard to jurisdictional claims in published maps and institutional affiliations.

Copyright: (c) 2021 by the authors. Licensee MDPI, Basel, Switzerland. This article is an open access article distributed under the terms and conditions of the Creative Commons Attribution (CC BY) license (https:// creativecommons.org/licenses/by/ $4.0 /)$.

\begin{abstract}
This study aimed to develop on-road NOx emission factors for Euro 6b light-duty diesel trucks (LDDTs) in Korea. On-road NOx emissions were measured using portable emissions measurement systems and compared with those measured using the Korean Driving Cycle (KDC), the conventional laboratory test used to develop emission factors. To ensure the representativeness of the LDDTs emission factors, five vehicles of three models were driven along two real driving routes for total traveled mileage of $2280 \mathrm{~km}$. On-road NOx levels were 2.1 to 6.9 times higher on average than those measured using the KDC because the latter does not cover the wide variability in vehicle speed and relative positive acceleration, common in real driving conditions. The lean-NOx trap was found to have disappointingly low NOx reduction efficiency in on-road driving. The on-road NOx emission factors by vehicle speeds developed in this study were comparable to the COPERT 4 factors.
\end{abstract}

Keywords: Euro 6b; Real Driving Emissions (RDE); emission factor; light-duty diesel truck; nitrogen oxide

\section{Introduction}

The Korean government established the Clean Air Policy Support System (CAPSS) to estimate the emission inventories of air pollutants and implement a range of emission control measures for different sources of pollution. Nitrogen oxides (NOx), which are a class of major atmospheric pollutants, act as precursors in the photochemical formation of tropospheric ozone [1] and contribute to the secondary formation of $\mathrm{PM}_{2.5}$.

Road transport is known as the major source of NOx emissions; it accounts for $53.7 \%$ of the total NOx emissions in the Seoul metropolitan area according to CAPSS statistics for 2016 [2]. Among the emission sources of road transport, diesel trucks account for $53.0 \%$ of the NOx emissions; the light-duty diesel trucks (LDDTs) that carry a one-ton load, in particular, account for $69.5 \%$ of the registered diesel trucks [3] and $30.2 \%$ of the NOx emissions and are thus particularly significant sources that need to be controlled.

The government has been tightening vehicle emissions standards to reduce the amount of air pollution generated by road transport and has adopted the Euro regulations set by the European Union on LDDTs. LDDTs running in Korea are defined as N1-class vehicles according to the categories in the European regulation [4], and vehicles certified after September 2015 are to meet the Euro 6b emission standards [5].

Several studies that measured gaseous emissions in real driving conditions with portable emissions measurement system (PEMS) found that there were substantial differences between NOx emissions measured with diesel vehicles driven in the laboratory and on-road conditions. In on-road driving, Euro $6 \mathrm{~b}$ light-duty vehicles were shown to have NOx levels considerably higher than the laboratory emission limit $(0.08 \mathrm{~g} / \mathrm{km})$ based on the New European Driving Cycle (NEDC). For European diesel vehicles, Degraeuwe and Weiss [6] showed the median of on-road NOx for seven Euro 4-6 diesel vehicles exceeded by 2.7 times those measured on the NEDC and the analysis of PEMS data from 39 Euro $6 \mathrm{~b}$ diesel passenger cars by O'Driscoll et al. [7] exhibited wide variability in NOx emissions 
from 1 to 22 times of the laboratory limit $(0.08 \mathrm{~g} / \mathrm{km})$ with the average of $0.36 \mathrm{~g} / \mathrm{km}$. For Korean diesel vehicles, Cha et al. [8] measured on-road NOx for 17 Euro $6 \mathrm{~b}$ diesel vehicles equipped with lean-NOx trap (LNT) or selective catalytic reduction (SCR) and the averaged on-road NOx was 6.6 times of laboratory limit.

The various on-road driving conditions could affect the increased NOx emissions from diesel vehicles. Lujan et al. [9] suggested that lower speeds with more accelerations and decelerations lead to high NOx emissions in urban driving. Gallus et al. [10] showed on-road NOx emissions increased linearly with road grade due to the higher engine load points. Kwon et al. [11] indicated that on-road NOx emissions were increased in the operation of air-conditioner and at low ambient temperature. Some studies, however, showed the excessive on-road NOx emissions could be caused by the characteristics or control strategies of emission reduction systems for diesel vehicles. Chong et al. [12] concluded that high on-road NOx can be attributed to not only high velocity with high acceleration but also low exhaust gas recirculation (EGR) mass flowrate and the oxidation of particulate matters during diesel particulate filter (DPF) regeneration. Degraeuwe and Weiss [6] demonstrated with their filtering method that emission control strategies used during NEDC testing for diesel cars must be inactive or modulated on the road even if vehicles are driven under certification-like conditions. Andersson et al. [13] indicated that the cold start and DPF regenerations were shown to have significant impacts on the emissions from diesel vehicles and excluding them from PEMS route results may result in unrepresentative emissions data for the vehicles. The assessment of NOx emissions from 73 Euro $6 \mathrm{~b}$ diesel vehicles by Yang et al. [14] showed the LNT-equipped Euro 6b diesel vehicles exhibited the poorer NOx emission performance over worldwide harmonized light-duty test cycle (WLTC), the more realistic driving test compared with SCR.

To resolve the NOx inconsistencies between the two sets of driving conditions and reduce NOx emissions more effectively, on-road emissions measurements based on the PEMS were adopted in recent emission regulations [15]; Korean LDDTs certified after 1 September 2018 are tested under the Real Driving Emissions (RDE) regulations, as are European N1-class vehicles. The enhanced SCR technologies have been applied to lightduty diesel vehicles to be compliant with new RDE regulations, Euro 6d-TEMP and Euro $6 \mathrm{~d}$. Innovative combustion systems also have been developed to be able to improve $\mathrm{CO}_{2}$ and NOx-soot trade-offs such as specific bowl design [16], innovative fuel injection systems, and injection strategy [17], which could reduce the usage of after-treatment systems with improving efficiency and performance.

Real driving conditions need to be reflected in the development of emission factors to ensure that the emissions inventories of air pollutants are estimated realistically. The Korea Driving Cycle (KDC) is a Korean laboratory test procedure that has been known to reflect typical Korean driving patterns [18]; instead of the NEDC, this test was used to develop the emission factors of air pollutants generated by vehicles in Korea. Given past problems regarding on-road NOx emissions of diesel vehicles, it is necessary to confirm if the KDC-based NOx emission factors for LDDTs are valid as representations of the on-road emission characteristics.

Although EU emission regulations have been implemented to Korean LDDTs, the market has been dominated by domestic manufacturers with a very low market share of imported vehicles. Therefore, it would not be appropriate to use COPERT emission factor of EU in calculating emission inventories for Korean LDDTs. Some Korean studies on real-driving NOx emissions have been done for passenger cars $[8,11,12]$ and heavy-duty vehicles [19], but the data for LDDTs has not been sufficient to develop emission factors for emission inventories.

In this study, NOx emissions were measured for five LDDTs using the KDC and RDE with PEMS. The results were then compared to enable the development of NOx emission factors that determine which test method is effective for reflecting Korean driving conditions, and the driving parameters were analyzed to find what factors cause differences in NOx emissions measured in the laboratory and real driving conditions. The on-road 
NOx emission factors were developed with $1 \mathrm{~km}$-section data analysis and validated with EU COPERT 4 factors to suggest for use in the Korean CAPSS inventories.

\section{Materials and Methods}

\subsection{Test Vehicles}

Images and the key specifications of five LDDTs used as test vehicles in this study represent three vehicle models and are listed in Table 1 and Figure 1.

Table 1. Key specifications for test vehicles.

\begin{tabular}{ccccccc}
\hline Vehicle ID & Transmission & Emission Standard & Engine Volume(L) & Model Year & Mileage (km) & Emission Control System \\
\hline V1 & Automatic & Euro 6b & 2.2 & 2018 & 6913 & \\
V2 & Automatic & Euro 6b & 2.5 & 2018 & 49,492 & EGR $^{1}$ \\
V3 & Automatic & Euro 6b & 2.5 & 2018 & 341 & DOC $^{2}$ \\
V4 & Manual & Euro 6b & 2.5 & 2018 & 20,087 & LNT $^{3}$ \\
V5 & Manual & Euro 6b & 2.5 & 2018 & 14,839 & DPF $^{4}$ \\
\hline
\end{tabular}

${ }^{1}$ EGR: exhaust gas recirculation; ${ }^{2}$ DOC: diesel oxidation catalyst; ${ }^{3}$ LNT: lean NOx trap; ${ }^{4}$ DPF: diesel particulate filter.
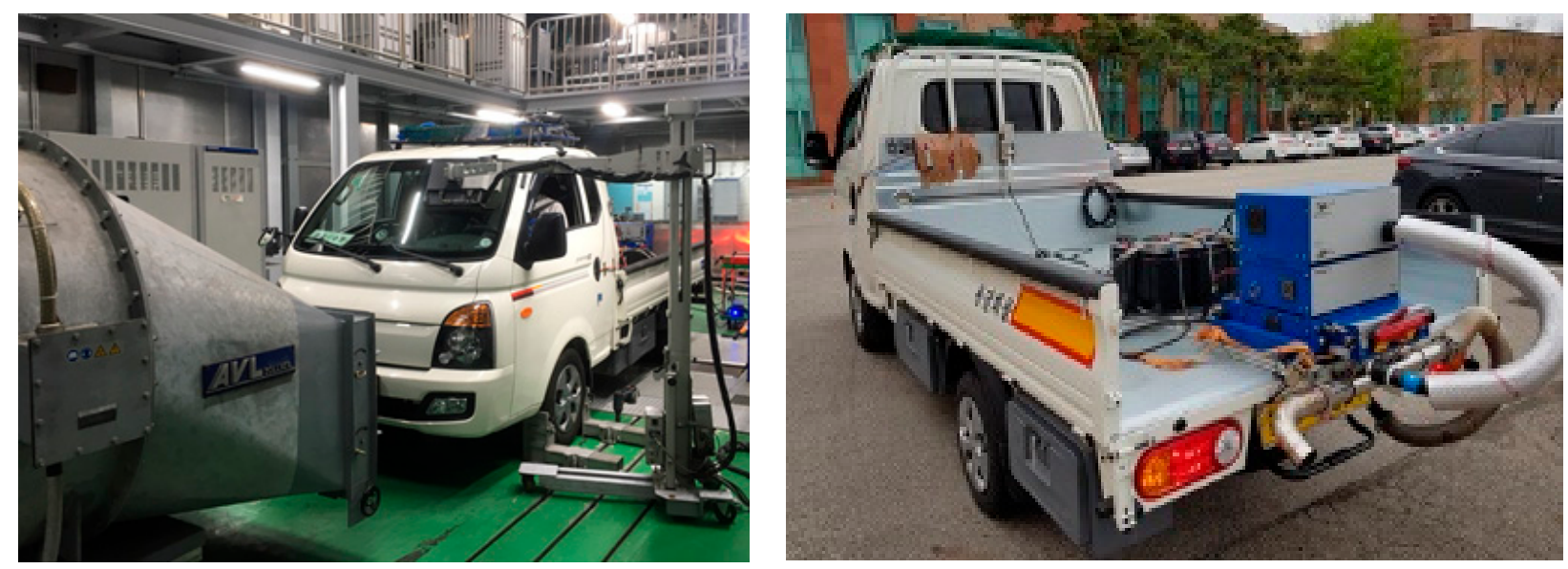

Figure 1. Emission tests on a chassis dynamometer in a laboratory and real driving conditions.

In Korea, LDDTs are commonly used to transport freight of one ton or less in large cities. The three models accounted for $88 \%$ of the light-duty truck market in Korea in 2018 [20]. Each has an engine volume of $2.2 \mathrm{~L}$ or $2.5 \mathrm{~L}$. Both the manual and automatic transmission variants of the models having the largest and second-largest market share were tested. All the vehicles were certified to the Euro $6 \mathrm{~b}$ emissions requirements, which has an acceptable limit of $0.125 \mathrm{~g} / \mathrm{km}$ for NOx emissions when measured using the NEDC.

Test vehicles were equipped with a NOx emission control system using EGR and LNT technologies. EGR, which has long been used in diesel engines, works by recirculating a portion of the exhaust gas from an engine back to the combustion chamber, thereby lowering temperatures therein and consequently reducing the quantity of NOx generated in the combustion chamber. LNT is an after-treatment technology based on the concept of trapping NOx emissions as nitrates during lean operating conditions and then, reducing the trapped nitrates to $\mathrm{N}_{2}$ and releasing it by regenerating with rich fuel control. LNT technology has seen general widespread use in Euro $6 \mathrm{~b}$ diesel vehicles.

\subsection{Laboratory Tests}

For this study, the laboratory measurements of emissions were conducted in the chassis dynamometer lab at the National Institute of Environment Research (NIER). To examine the validity of the laboratory test and develop the emission factors with the conventional method, tests were run using the NEDC and the WLTC, which are emission certification test cycles and the KDC, as shown in Figure 2. 

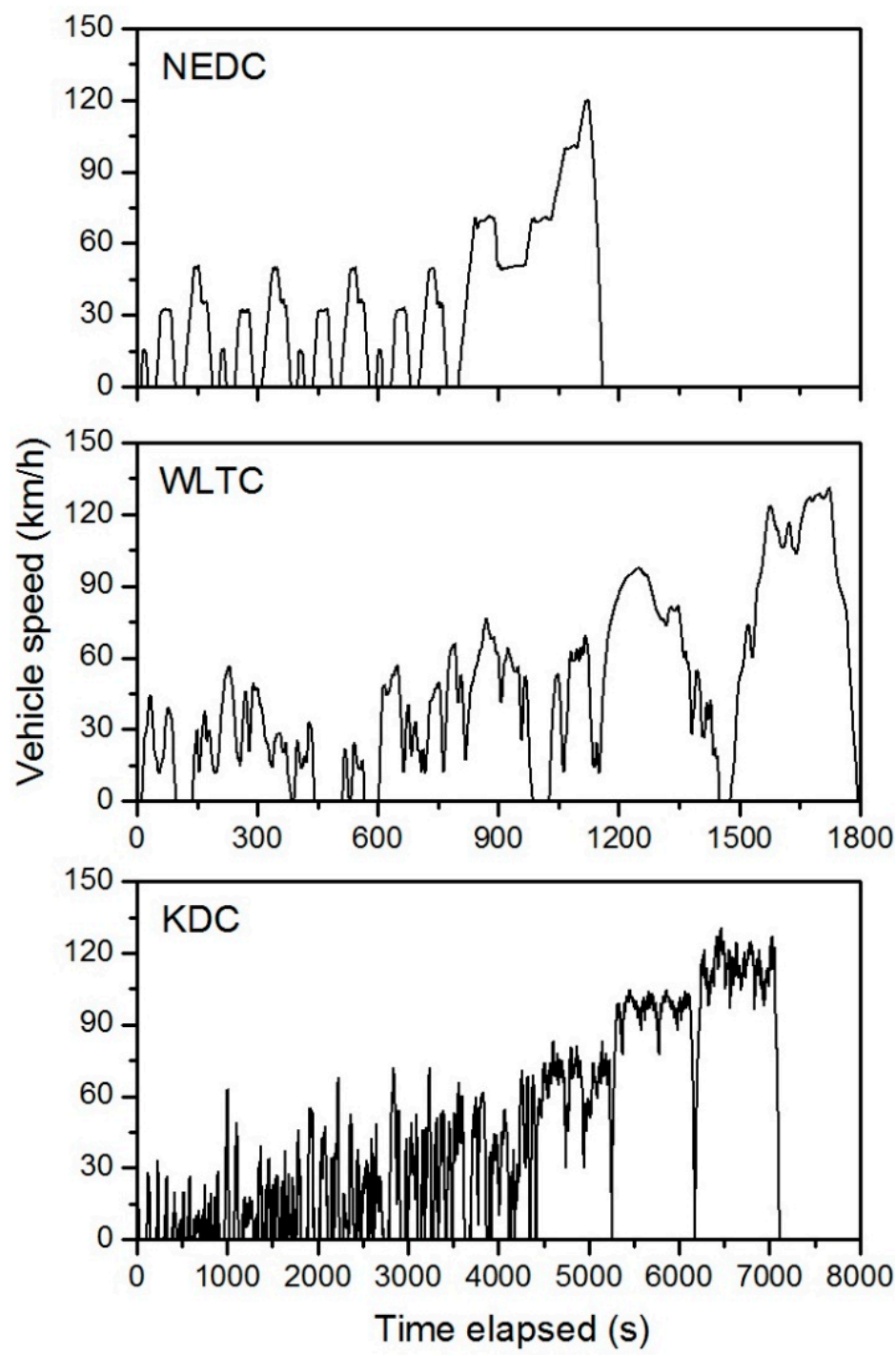

Figure 2. Driving profiles for laboratory emission tests. NEDC: New European Driving Cycle; WLTC: worldwide harmonized light-duty test cycle; KDC: Korea Driving Cycle.

The NEDC used to test emissions while certifying Euro $6 \mathrm{~b}$ vehicles consists of four lowspeed urban driving cycles and one high-speed extra-urban driving cycle specialized for emission tests and characterized by the constant acceleration. In Korea, vehicle certification tests have applied the WLTC procedure instead of the NEDC since September 2018. The WLTC is an international test cycle developed by the World Forum for the harmonization of vehicle regulations based on on-road driving data collected in Europe, the United States, Japan, Korea, and India; it is known for having driving dynamics that are closer to realworld driving patterns than those of the NEDC [21]. Test cycles used to develop emission factors for vehicles in Korea have been established by the NIER and consists of 15 driving cycles based on averaged vehicle speed [22]. The KDC is a combination of eight sub-driving cycles from a 15-driving cycle set and is assessed as a test mode that is highly representative of the driving patterns for Korean light-duty vehicles [18].

The road-load coefficients that are required to be input to a chassis dynamometer were established for NEDC pursuant to United Nations Regulation No. 83 [23]. It is beyond the scope of this study to determine whether the test vehicles are compliant with the emission requirements; the same road-load coefficients were used in all the laboratory tests in which the NOx emissions characteristics were evaluated according to the driving profiles described. 
The equipment used to measure emissions in the laboratory tests conducted as part of this study meets the requirements specified in UN Regulation No. 83 [23]; the AVL (Graz, Austria) 48" Chassis Dynamometer roller was used and exhaust gases were sampled with a constant volume sampler and measured using the Horiba (Kyoto, Japan) MEXA-7200H and 7100D systems.

\subsection{Real Driving Emissions Tests}

On-road emission tests based on the European Union (EU) "Real Driving Emissions of Light-Duty Vehicles (RDE-LDV)" [15] were conducted in Seoul and on its outskirts, on test routes R1 and R2, as shown in Figure 3.

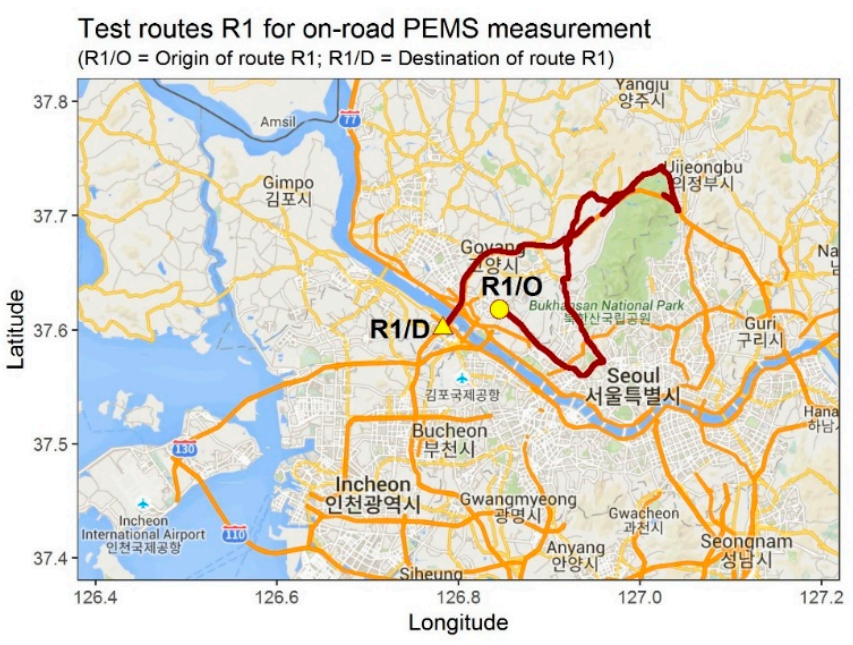

(a) Route1

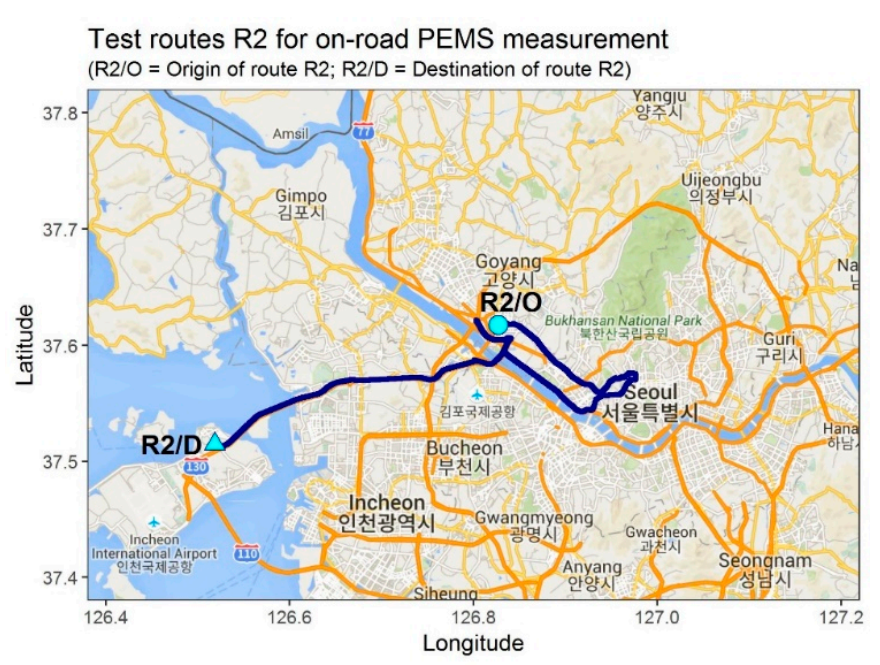

(b) Route2

Figure 3. Routes for on-road emission tests.

The type of road was divided by the vehicle speed, as prescribed by the EU RDELDV-less than $60 \mathrm{~km} / \mathrm{h}$ in the urban section, $60 \mathrm{~km} / \mathrm{h}$ to $90 \mathrm{~km} / \mathrm{h}$ in the rural section, and $90 \mathrm{~km} / \mathrm{h}$ or more on highways. This classification is in line with the speed limits based on road types in Korea. The tests were run a total of 30 times and $2280 \mathrm{~km}$ mileages. Test data with DPF regeneration was included in developing emission factors. The driving characteristics of the on-road test routes were compared with those of the driving cycles in laboratory tests (Table 2).

Table 2. Driving characteristics of on-road tests and laboratory cycles.

\begin{tabular}{cccccc}
\hline $\begin{array}{c}\text { Driving } \\
\text { Cycle/Route }\end{array}$ & $\begin{array}{c}\text { Mileage } \\
\mathbf{( k m})\end{array}$ & $\begin{array}{c}\text { Duration } \\
\mathbf{( m i n . )}\end{array}$ & $\begin{array}{c}\text { Average Vehicle Speed } \\
\mathbf{( k m} / \mathbf{h})\end{array}$ & $\begin{array}{c}\text { Maximum Vehicle Speed } \\
\mathbf{( k m} / \mathbf{h})\end{array}$ & $\begin{array}{c}\text { Stop Percentage of Urban Driving } \\
\mathbf{( \% )}\end{array}$ \\
\hline NEDC & 11.0 & 19 & 33.4 & 120.1 & - \\
WLTC & 23.3 & 30 & 46.5 & 131.2 & - \\
KDC & 89.6 & 118 & 45.4 & 130.6 & - \\
Route1 & 73.8 & 110 & 40.3 & 123.5 & 32.7 \\
Route2 & 75.4 & 108 & 41.9 & 125.7 & 33.0 \\
\hline
\end{tabular}

On-road emissions were measured by the second using PEMS. As shown in Figure 4, the PEMS (SEMTECH-LDV, SENSORS, Saline, MI, US) consists of a gas analyzer, flow meter, power supply, control unit, monitoring device, GPS, thermometer, and hygrometer. The exhaust flow meter with a pitot tube is used to translate concentration into mass. The vehicle speed is measured by the GPS, and the thermometer and hygrometer are used to measure ambient temperature and calculate correction factors, respectively. Electric power is supplied by the four $12 \mathrm{~V}$ batteries connected to the vehicles in parallel. The 
performance of the PEMS was verified with laboratory equipment in driving WLTC before the on-road tests.

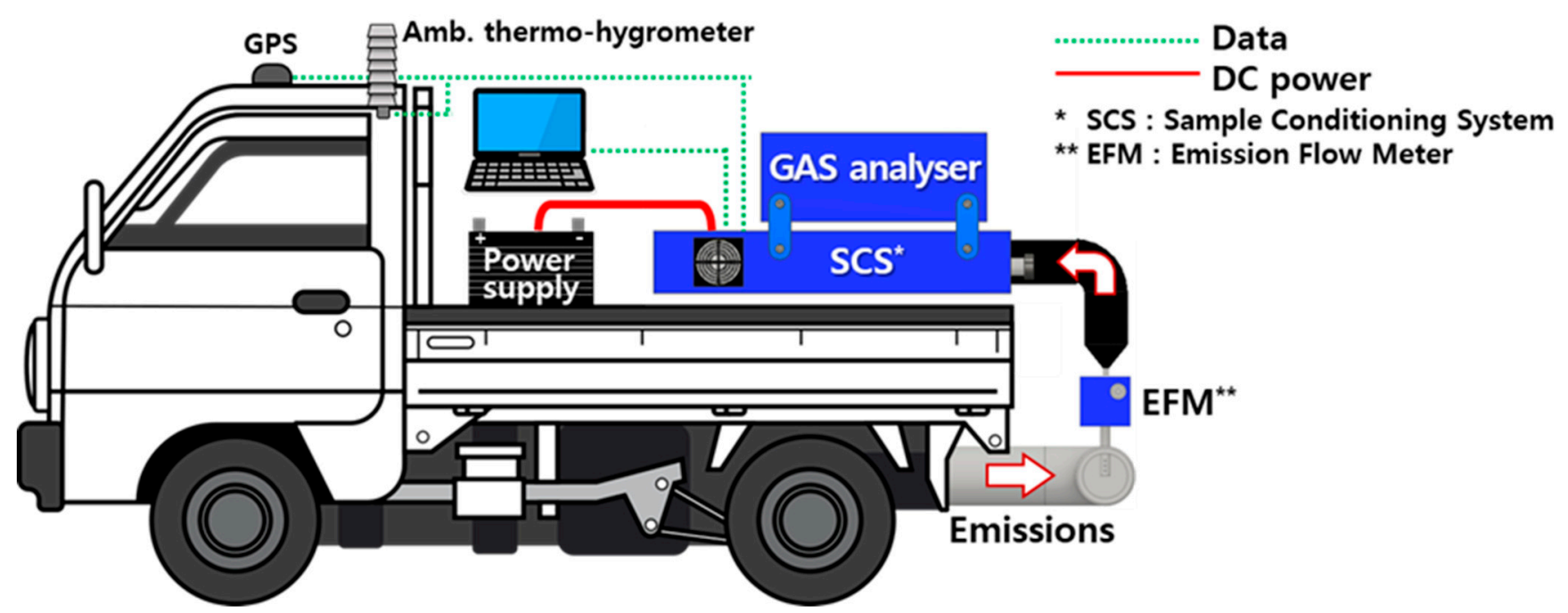

Figure 4. Diagram of the setup for the test vehicle installed with the portable emissions measurement system (PEMS) system.

\subsection{Data Analysis}

The NOx results in laboratory tests were calculated by applying the average concentration of the gas sampled in the dilution bag through the constant volume sampler system in each phase of the driving cycles. The emission factors for Korean vehicles were developed by analyzing the pollutant emissions by the average vehicle speed for each sub-cycle of the KDC.

In the on-road tests, the emission results were calculated based on the concentration and flow rate of the exhaust gas measured in seconds. The average values of the on-road test in this study were calculated with the moving averaging window (MAW) method prescribed in the EU RDE-LDV [15]. When developing emission factors using the on-road test results, the data manager for emission rates and activities of road transport (DEAR)-a $1 \mathrm{~km}$-section analysis method suggested by Lee et al. [18] — was applied. DEAR segments the pollutant emissions measured per second in $1 \mathrm{~km}$-sections and analyzes the average of the vehicle speeds and emissions for each section. The averaged values of the individual $1 \mathrm{~km}$-sections were binned to the unit of average speed at $10 \mathrm{~km} / \mathrm{h}$ to analyze the emissions characteristics according to the average vehicle speed.

\section{Results and Discussion}

\subsection{Comparisons of NOx Emissions from Real Driving Emissions (RDE) and Laboratory Tests}

Figure 5 shows the average NOx emissions for each test vehicle in the laboratory and RDE tests. The NEDC result for the V2 vehicle was not valid due to the setting of laboratory equipment. All five test vehicles showed higher NOx emissions in the latter than in the former. In the NEDC, NOx emissions were found to meet or slightly exceed the allowable limit of $0.125 \mathrm{~g} / \mathrm{km}$ under Euro $6 \mathrm{~b}$ standard.

The average NOx emissions from the test vehicles were $0.17-0.55 \mathrm{~g} / \mathrm{km}$ under the KDC and 0.13-1.0 g/ km under the WLTC. In the on-road measurements, the average NOx emissions were $0.55-1.83 \mathrm{~g} / \mathrm{km}$, which are 4.4-14.6 times higher than the allowable limits under the NEDC, with substantial variance among the test vehicles.

The difference in the laboratory and RDE NOx emissions results in this study is similar to those from other studies of on-road NOx emissions of Euro 6b-certified lightduty diesel vehicles. These previous studies explained the excessive NOx emissions in RDEs by noting that emission control technologies applied to Euro 6b LDDTs, including EGR and LNT, are not sufficient to offset NOx increases caused by external factors such as ambient temperature, steep roads, and acceleration. The same reasons seem to apply to the 
results of this study, where test vehicles showed a significant increase in NOx emissions in real driving conditions compared to other laboratory test conditions.
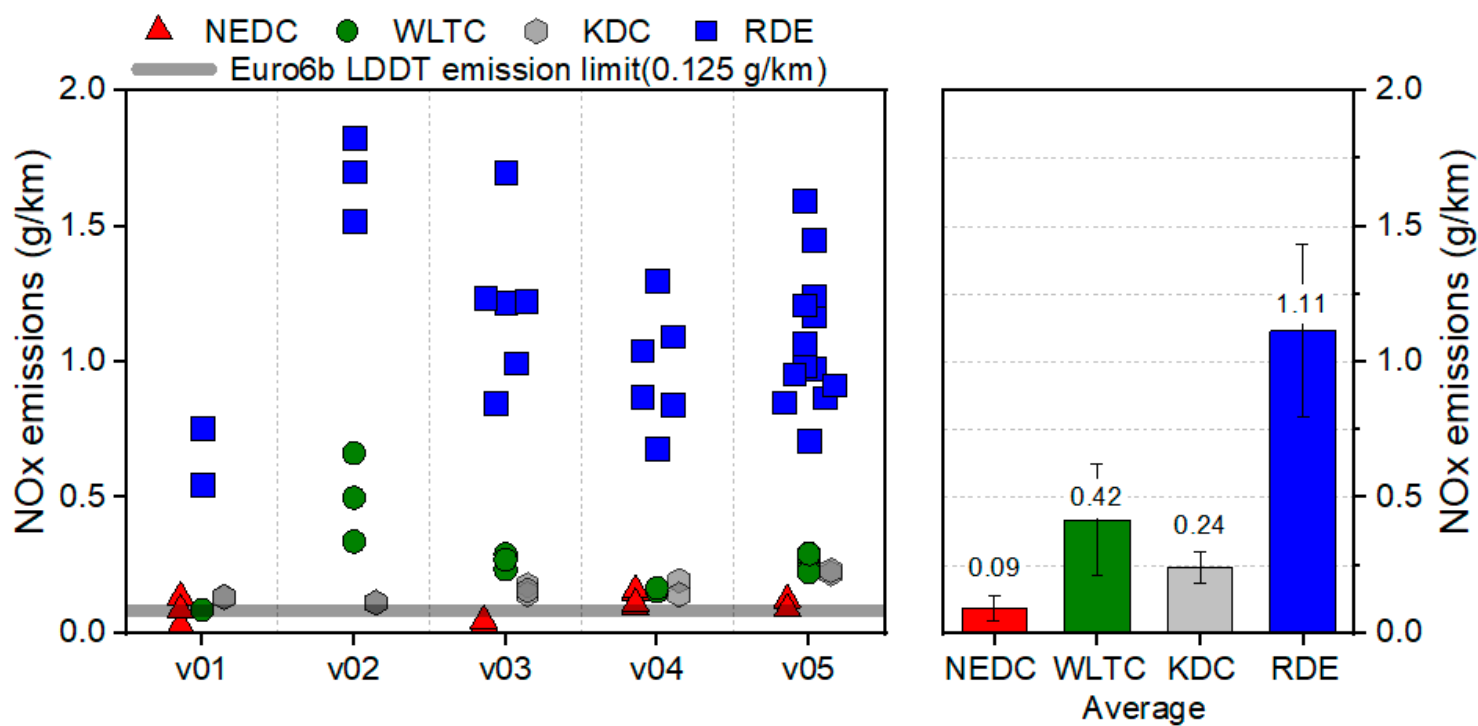

Figure 5. Results of average NOx emissions for each test vehicle under laboratory tests (NEDC: New European Driving Cycle, WLTC: worldwide harmonized light-duty vehicle test cycle, and KDC: Korea Driving Cycle) and Real Driving Emissions (RDE) tests. The error bars express the standard deviations.

Given that on-road NOx emissions are 2.1-6.9 times higher than those measured under the KDC, it is necessary to develop NOx emission factors based on the RDE results to reflect realistic NOx emissions in the CAPSS inventory.

\subsection{Comparisons of NOx Emissions from RDE and Laboratory Tests Based on Average Vehicle Speed}

The Korean CAPSS system has estimated the emission inventories of vehicles using emission factors according to the average vehicle speed based on the results of KDC emission tests. Figure 6 shows the results of the RDE tests as a box plot after the average NOx emissions of a $1 \mathrm{~km}$-section were binned by average vehicle speeds. The results of the KDC test are represented by the average NOx emissions from the eight sub-cycles by average vehicle speed. In all sections, the amount of on-road NOx emissions are significantly higher than those from the KDC test.

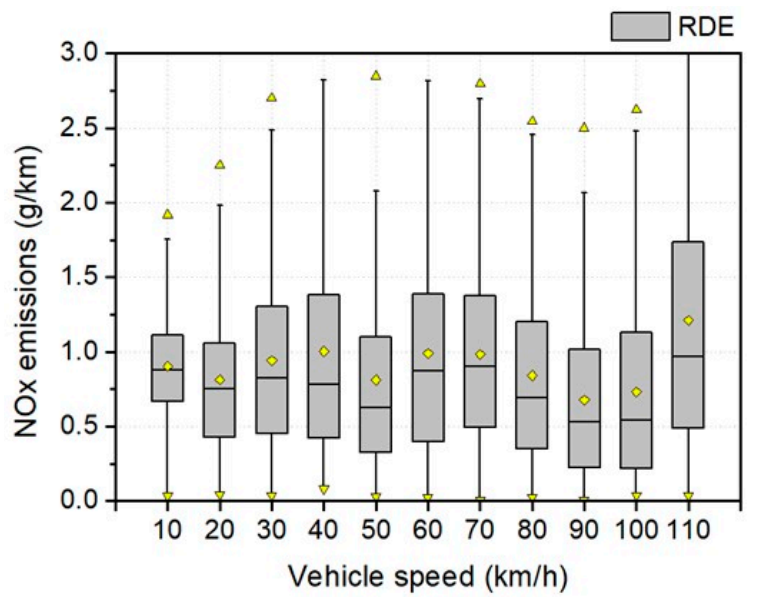

(a)

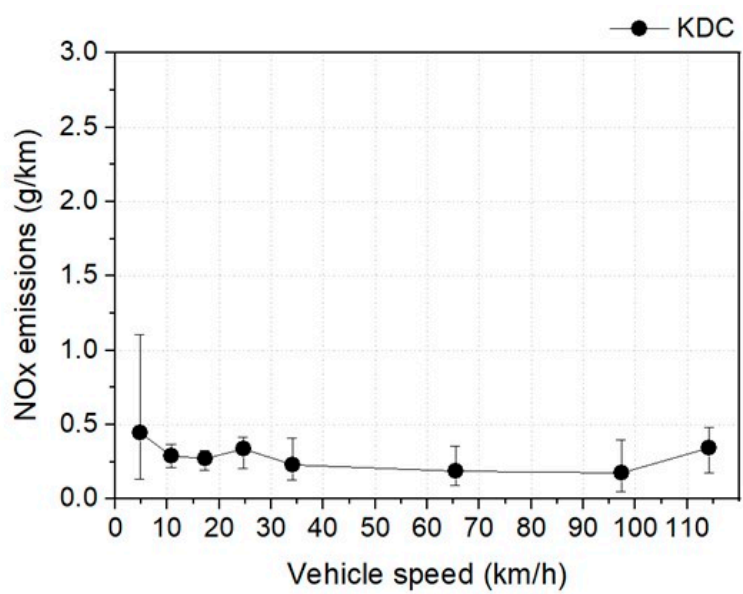

(b)

Figure 6. Results of NOx emissions by vehicle speed under the Real Driving Emissions (RDE) and Korea Driving Cycle (KDC) tests. (a) The 1-km section analysis for RDE tests and (b) averaged emissions in each sub-cycle of KDC. 
Compared to results of KDC, the average NOx emissions in the RDE test were 2.8 times higher in the urban section at an average speed of $50 \mathrm{~km} / \mathrm{h}$ or less, 4.9 times higher in the rural section at an average speed of $60-80 \mathrm{~km} / \mathrm{h}$, and 3.4 times higher on motorways at an average speed of $90 \mathrm{~km} / \mathrm{h}$. The NOx emissions per $1 \mathrm{~km}$ unit tended to increase at low and high speeds under the KDC, while the results of on-road tests were high in the overall average vehicle speed. Although the KDC is considered to reflect the typical driving patterns in Korea, the results of this study show that it has limitations in terms of how it represents the NOx emissions of Euro 6b LDDTs in real driving conditions.

\subsection{Examining the Difference in NOx Emissions in Results from RDE and Laboratory Tests 3.3.1. Influence of Driving Dynamics}

To examine the difference in NOx emissions generated from the RDE and KDC, we used the test results of vehicle V4. Figures 7 and 8 show the NOx emissions based on vehicle speed and relative positive acceleration (RPA) for the RDE and KDC, respectively.

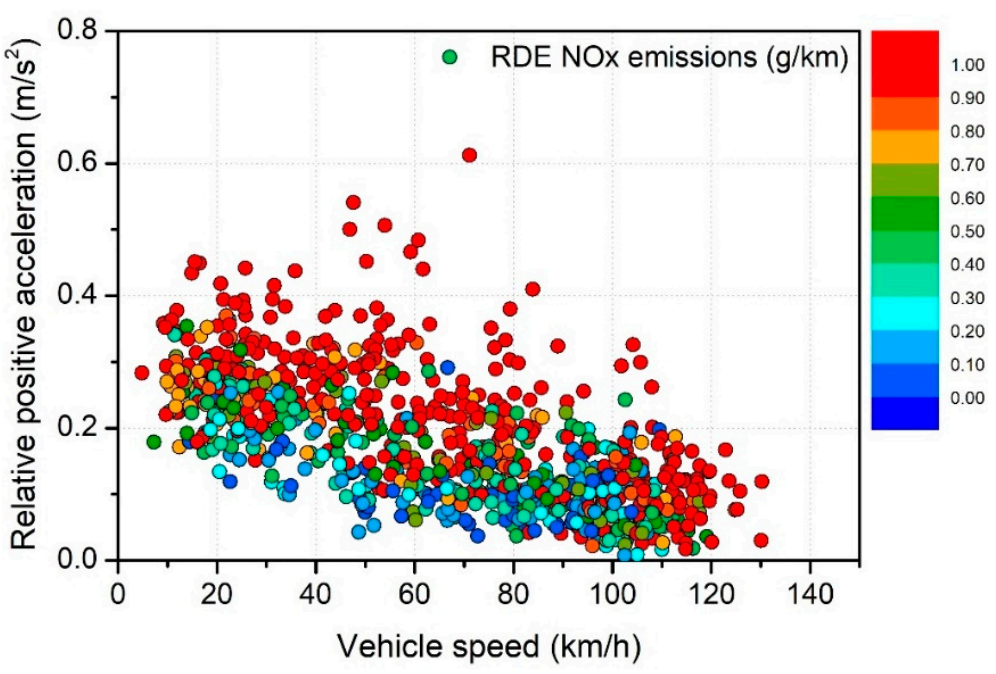

Figure 7. NOx emissions according to vehicle speed and relative positive acceleration in the Real Driving Emissions (RDE) test.

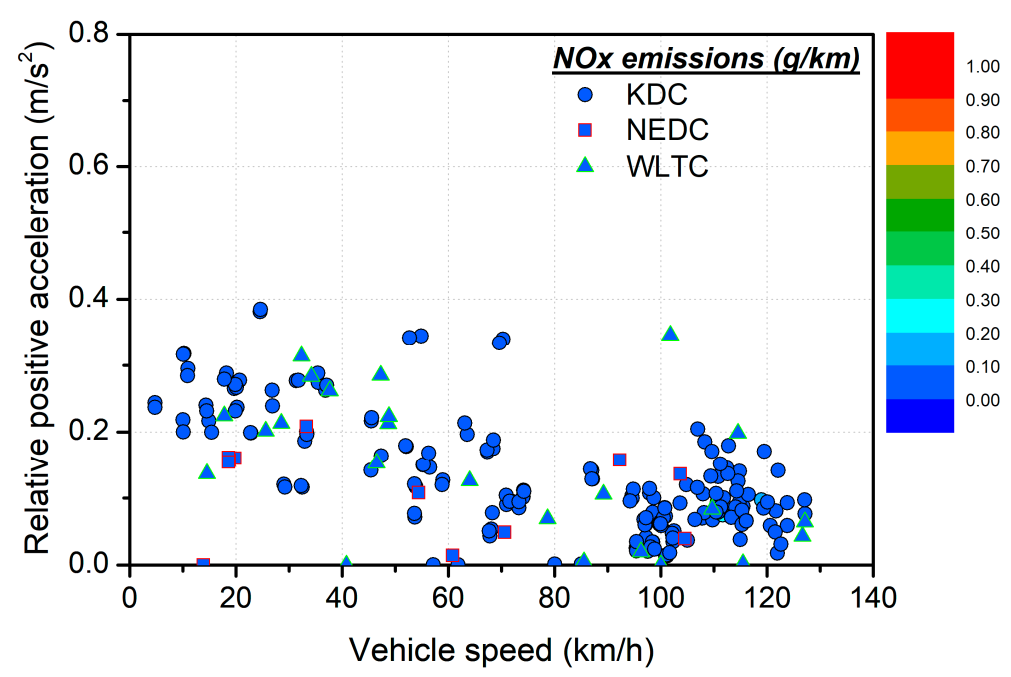

Figure 8. NOx emissions according to vehicle speed and relative positive acceleration of the laboratory Korea Driving Cycle (KDC) test.

Figure 7 shows that the higher the RPA, the higher the average NOx emissions are when vehicle speeds are similar. The NOx emissions vary according to the average vehicle speed as reported in previous studies [7,9]. A high RPA increases the load on 
the engine during acceleration. According to the Netherlands Vehicle Authority [24], the EGR technology employed in diesel engines decreases the rate of operation to protect the engine as a greater load is placed on it. A comparison of the average vehicle speed-RPA distributions shows that RDE tests have higher RPAs than those of the KDC. It seems clear the KDC has limitations in terms of representing real driving dynamics although it is considered to reflect average driving patterns in Korea.

Figure 8, however, shows that the NOx emissions under the KDC are lower than those of the RDE tests at the similar average vehicle speed and RPA. This can be explained via the NOx emissions of Euro 6b LDDTs being influenced by more than just driving dynamics. Degraeuwe et al. [6] showed that the NOx emissions of the RDE test were still higher than the NEDC even when RDE data filtered with vehicle speed, acceleration, $\mathrm{CO}_{2}$ emissions, and ambient temperature was compared with the NEDC data having similar driving dynamics. This suggests that the difference in NOx emissions is due to the different driving dynamics and different control strategies adopted by manufacturers for laboratory and real driving conditions. The results of this study for the NOx emissions of Euro $6 \mathrm{~b}$ LDDTs can also be explained by the fact that the performance of the NOx emission control technologies would not be maintained in real driving conditions.

\subsubsection{Influence of NOx Emission Control System}

EGR and LNT technologies used in the test vehicles are generally applied to Euro $6 \mathrm{~b}$ diesel engines. However, some studies $[25,26]$ have confirmed that EGR systems do not function well in driving conditions apart from the NEDC. In this study, we found that there are also significant differences in NOx reduction performance of LNT under real driving conditions and NEDC.

Figure 9 shows the LNT operational characteristics for V4, with modal NOx and CO emissions under both the RDE and NEDC tests. LNT technology reduces NOx emissions via a process referred to as "de-NOx regeneration," in which NOx is stored under lean conditions, general operating conditions of diesel engines, and then reduced via control of a temporary stoichiometric or rich air-fuel ratio. According to Matsumoto et al. [27], CO concentrations peak during the regeneration period due to the incomplete fuel combustion, whereas NOx concentrations reach the peak value due to the NOx slip. Under the NEDC, a low NOx emission level is achieved when both the storage of NOx and de-NOx regeneration function properly. Under real driving conditions, peaks in CO concentration are observed several times, implying that the storage and de-NOx regeneration occur with LNT operation. The time between the moments when the CO levels peak is when the LNT catalysts store NOx but the NOx emission rate is substantially higher in real driving conditions than they are during the NEDC. Even during the de-NOx generation of LNT in real driving, the NOx emissions increase because its reduction performance is lower than that of NEDC.

Vehicle manufacturers control NOx emissions using this technology by modeling the amount of NOx that the LNT can store and the amount of fuel required to reduce the stored NOx. LNT emission control technology works quite well under simple driving conditions, such as those of the NEDC; however, its function is limited under real driving conditions when a variety of driving parameters affect NOx emissions. Better NOx emissions can be achieved if some peaks of NOx are mitigated with an improved calibration strategy during transient maneuvers. 


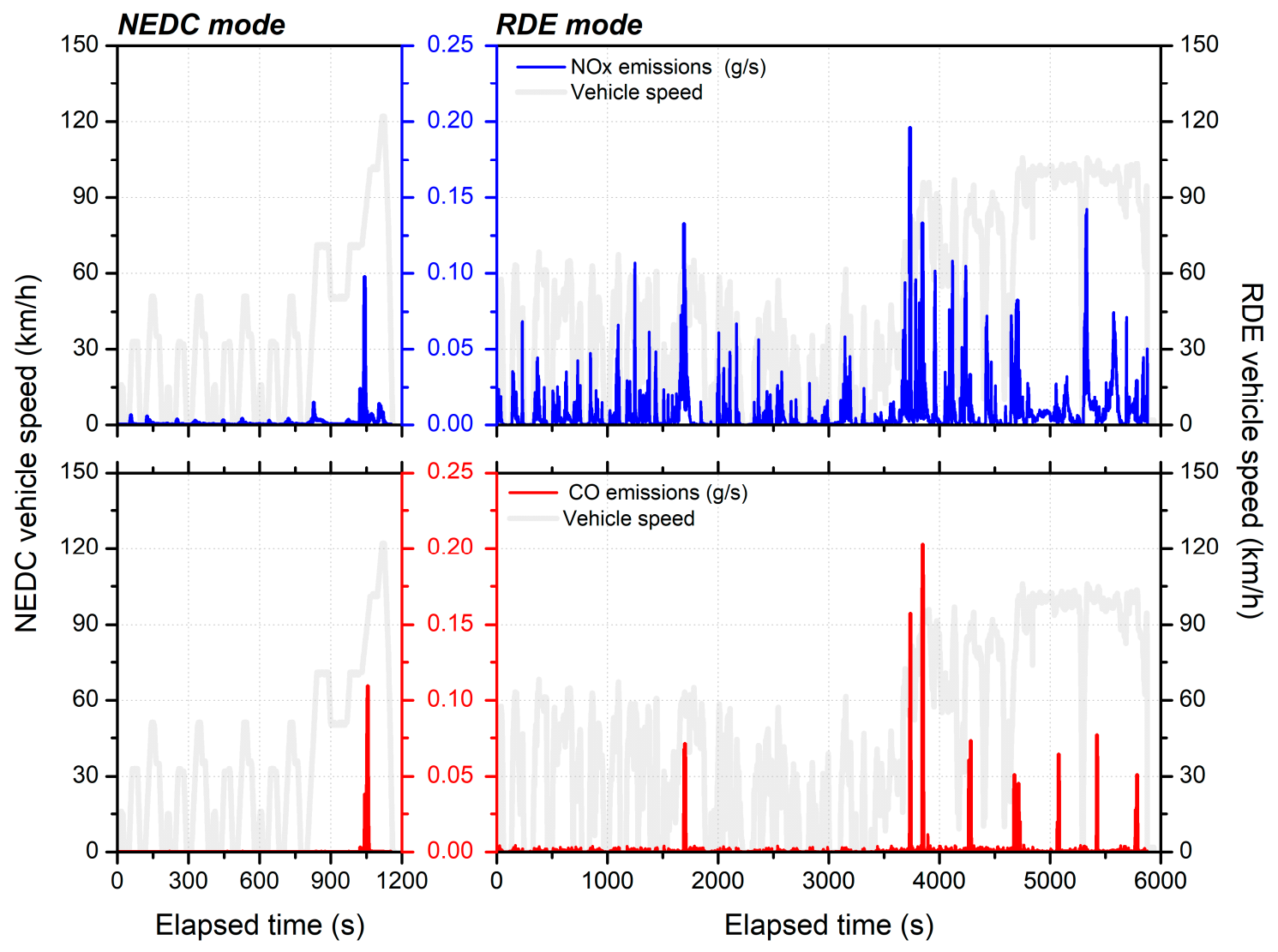

Figure 9. Operational characteristics of the lean-NOx trap (LNT) in Real Driving Emissions (RDE) and New European Driving Cycle (NEDC) test conditions.

\subsection{Validation of On-Road NOx Emission Factors}

As confirmed by the results of the tests carried out in this study, the NOx emissions of Euro $6 \mathrm{~b}$ LDDTs are influenced by various driving parameters and EGR and LNT technologies have a limited ability to control NOx emissions under a wide range of on-road driving conditions. Therefore, it is necessary to consider a number of environmental factors that affect NOx emissions in real driving conditions-various driving patterns, road load, ambient temperature, and road steepness-to develop realistic NOx emissions for Euro $6 \mathrm{~b}$ LDDTs. Because it is difficult to reflect the various driving parameters in averaged or normalized laboratory driving cycles, it would be more effective to develop emission factors using data measured in RDE tests.

Figure 10 compares the Euro 6b LDDT emission factors developed in this study, based on a DEAR analysis of the on-road NOx emissions, with those from European studies [28]. The NOx emission factors developed for LDDTs based on RDE results show a remarkable difference compared to those with laboratory KDC tests. The on-road NOx emission factors for Euro 6b LDDTs developed in this study were similar to those in COPERT 4 [29]. While NOx emission factors in COPERT 4 show higher levels at both low and high speeds than those developed in this study, the latter displays a smaller difference in NOx emissions in the overall average vehicle speed.

Therefore, it appears to be more reasonable to use emission factors developed from the data measured in RDE tests, compared to laboratory measurements, if the NOx emission characteristics of Korean Euro 6b LDDTs are to be reflected realistically. 


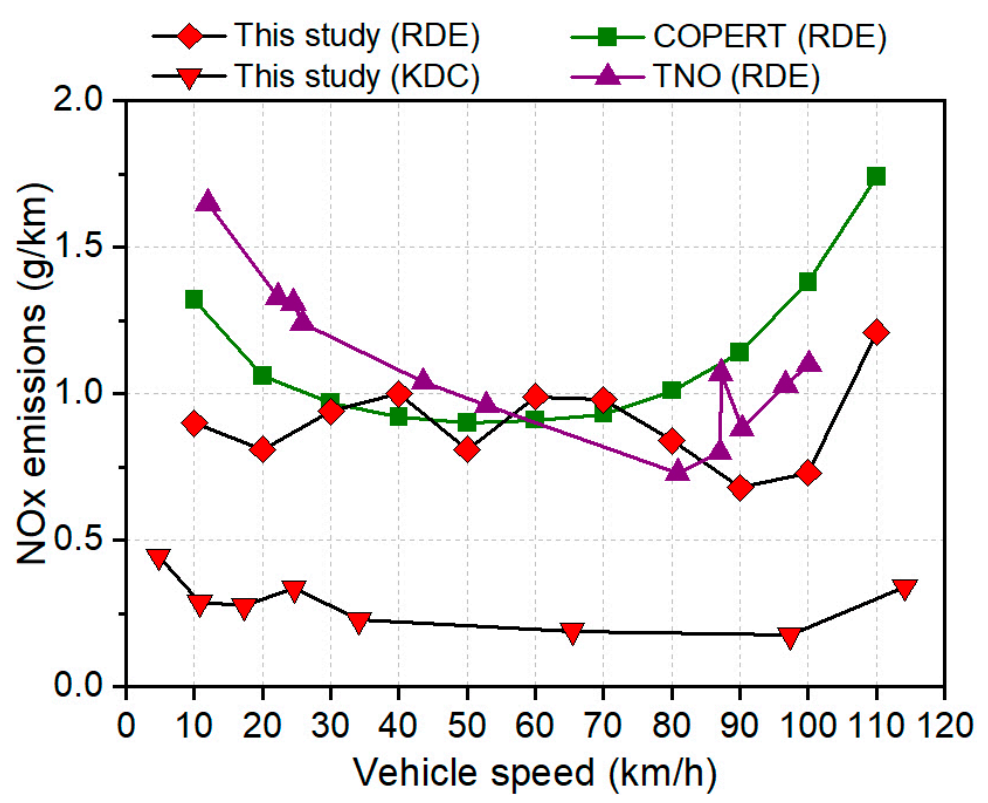

Figure 10. Comparison of NOx emission factors with previous studies.

\section{Conclusions}

We measured NOx emissions for five test vehicles using both laboratory test procedures and real driving conditions to develop the NOx emission factors for Euro $6 \mathrm{~b}$ LDDTs in Korea. In this study, although the test data in DPF regeneration was included to develop NOx emission factors, the increased NOx emissions by DPF regeneration were not accurately quantified. It is difficult to quantify the increased NOx emissions in this event because the control of DPF regeneration would be affected by the accumulated soot amount in the filter, additive fuel injection that is controlled by the engine control unit depending on various driving conditions, durations of DPF regeneration, and other driving parameters. Although it is known that NOx emissions from Euro $6 \mathrm{~b}$ diesel vehicles are deviated by ambient temperature, in this study, the seasonal effects were not estimated to develop NOx emission factors. Despite these limitations, this study suggests more realistic NOx emission factors of Euro $6 \mathrm{~b}$ LDDTs in the Korean driving conditions by selecting representative models as test vehicles and conducting on-road emission tests in Seoul, which has the biggest traffic volume in Korea. The conclusions of this study could be summarized as follows:

- The average on-road NOx emissions of the Euro 6b LDDTs were 4.4-14.6 times higher than those measured with the NEDC, an emission certification test cycle. The NOx levels were also 2.1-6.9 times higher on average than those measured with the KDC, a conventional test procedure used to develop emission factors in Korea;

- The KDC can be considered to represent typical driving patterns in Korea; however, it fails to cover a wide range of average vehicle speeds and RPA in real driving conditions. In particular, the KDC had limitations in terms of capturing excessive NOx emissions observed under driving conditions when the RPA was high;

- The NOx storage and de-NOx regeneration in LNT technology, adopted as part of NOx after-treatment equipment used for Euro 6b LDDTs in Korea, performed well under the NEDC, but insufficiently, in terms of achieving low NOx emissions levels, in real driving conditions;

- The NOx emission factors according to average vehicle speed, developed in this study via RDE tests, were comparable to those suggested in COPERT 4, thereby showing a remarkable difference from the NOx emission factors developed through conventional laboratory emission tests. Therefore, realistic NOx emission factors for Euro 6b LDDTs in Korea should be based on emission factors developed from data measured in real driving conditions. 
The results of this study will be suggested for use in the Korean CAPSS inventory. The conclusion of this study will contribute to estimate realistic NOx emission amount from Euro 6b LDDTs in Korea and the developed NOx emission factors can be used in other countries having applied Euro emission regulations because the results of this study were validated with COPERT 4 . On the other hand, COPERT 4 emission factors based on the on-road measurement could be backed up with this study. Furthermore, it can provide a justification of the emission control measures for light-duty trucks such as the early introduction of electric trucks with subsidies by the Korean Ministry of Environment.

Author Contributions: Conceptualization, S.R. and J.P.; methodology, S.R. and M.S.; validation, S.R., J.P., and M.S.; investigation, M.S.; resources, J.L.; data curation, S.R. and M.S.; writing-original draft preparation, S.R.; writing - review and editing, J.P.; visualization, S.R. and M.S.; supervision, J.L.; project administration, M.S.; funding acquisition, J.L. All authors have read and agreed to the published version of the manuscript.

Funding: This research was funded by the National Institute of Environmental Research (NIER), grant number NIER-RP2018-122.

Institutional Review Board Statement: Not applicable.

Acknowledgments: We thank the dedicated personnel at the National Institute of Environmental Research (NIER) for all their assistance.

Conflicts of Interest: The authors declare no conflict of interest.

\begin{tabular}{ll}
\multicolumn{2}{l}{ Abbreviations } \\
CAPSS & Clean Air Policy Support System \\
NOx & Nitrogen oxides \\
LDDTs & Light-duty diesel trucks \\
PEMS & Portable emissions measurement system \\
NEDC & New European driving cycle \\
LNT & Lean-NOx trap \\
SCR & Selective catalytic reduction \\
EGR & Exhaust gas recirculation \\
DPF & Diesel particulate filter \\
WLTC & Worldwide harmonized light-duty test cycle \\
KDC & Korean driving cycle \\
DOC & Diesel oxidation catalyst \\
RDE-LDV & Real driving emissions of light-duty vehicles \\
MAW & Moving averaging window \\
DEAR & Data manager for emission rates and activities of road transport \\
RPA & Relative positive acceleration \\
COPERT & Computer programme to calculate emissions from road transport
\end{tabular}

\section{References}

1. Yao, Z.; Wu, B.; Wu, Y.; Cao, X.; Jiang, X. Comparison of NOx emissions from China III and China IV in-use diesel trucks based on on-road measurements. Atmos. Environ. 2015, 123, 1-8. [CrossRef]

2. Clean Air Policy Support System (CAPSS). National Air Pollutant Emission Report 2016. Available online: http://airemiss.nier. go.kr/mbshome/mbs/airemiss/index.do (accessed on 29 December 2020). (In Korean)

3. Korea Automobile Manufacturers Association (KAMA). Vehicle Registration Statistics 2016. Available online: http: / / www.kama.or.kr/NewsController?cmd=V\&boardmaster_id=Register\&board_id=390\&menunum=0003\&searchGubun= \&searchValue $=\&$ pagenum $=5$ (accessed on 29 December 2020). (In Korean)

4. European Union (EU). Directive 2007/46/EC of the European Parliament and of the Council of 5 September 2007 Establishing a Framework for the Approval of Motor Vehicles and Their Trailers, and of Systems, Components and Separate Technical Units Intended for such Vehicles. Available online: https:/ / eur-lex.europa.eu/eli/dir/2007/46/oj (accessed on 29 December 2020).

5. European Union (EU). Commission Regulation (EU) 2012/459 of 29 May 2012 Amending Regulation (EC) No $715 / 2007$ of the European Parliament and of the Council and Commission Regulation (EC) No 692/2008 as Regards Emissions from Light Passenger and Commercial Vehicles (Euro 6). Available online: https:/ /eur-lex.europa.eu/eli/reg/2012/459/oj (accessed on 29 December 2020). 
6. Degraeuwe, B.; Weiss, M. Does the New European Driving Cycle (NEDC) really fail to capture the NOX emissions of diesel cars in Europe? Environ. Pollut. 2017, 222, 234-241. [CrossRef] [PubMed]

7. O'Driscoll, R.; ApSimon, H.M.; Oxley, T.; Molden, N.; Stettler, M.E.; Thiyagarajah, A. A Portable Emissions Measurement System (PEMS) study of NOx and primary $\mathrm{NO}_{2}$ emissions from Euro 6 diesel passenger cars and comparison with COPERT emission factors. Atmos. Environ. 2016, 145, 81-91. [CrossRef]

8. Cha, J.; Lee, J.; Chon, M.S. Evaluation of real driving emissions for Euro 6 light-duty diesel vehicles equipped with LNT and SCR on domestic sales in Korea. Atmos. Environ. 2019, 196, 133-142. [CrossRef]

9. Lujan, J.M.; Bermudez, V.; Dolz, V.; Monsalve-Serrano, J. An assessment of the real-world driving gaseous emissions from a Euro 6 light-duty diesel vehicle using a portable emissions measurement system (PEMS). Atmos. Environ. 2018, 174, 112-121. [CrossRef]

10. Gallus, J.; Kirchner, U.; Vogt, R.; Benter, T. Impact of driving style and road grade on gaseous exhaust emissions of passenger vehicles measured by a Portable Emission Measurement System (PEMS). Transp. Res. Part D Transp. Environ. 2017, 52, 215-226. [CrossRef]

11. Kwon, S.; Park, Y.; Park, J.; Kim, J.; Choi, K.H.; Cha, J.S. Characteristics of on-road NOx emissions from Euro 6 light-duty diesel vehicles using a portable emissions measurement system. Sci. Total Environ. 2017, 576, 70-77. [CrossRef] [PubMed]

12. Chong, H.S.; Park, Y.; Kwon, S.; Hong, Y. Analysis of real driving gaseous emissions from light-duty diesel vehicles. Transp. Res. Part D Transp. Environ. 2018, 65, 485-499. [CrossRef]

13. Andersson, J.; May, J.; Favre, C.; Bosteels, D.; de Vries, S.; Heaney, M.; Keenan, M.; Mansell, J. On-road and chassis dynamometer evaluations of emissions from two Euro 6 diesel vehicles. SAE Int. J. Fuels Lubr. 2014, 7, 919-934. [CrossRef]

14. Yang, L.; Franco, V.; Mock, P.; Kolke, R.; Zhang, S.; Wu, Y.; German, J. Experimental assessment of NOx emissions from 73 Euro 6 diesel passenger cars. Environ. Sci. Technol. 2015, 49, 14409-14415. [CrossRef] [PubMed]

15. European Union (EU). Commission Regulation (EU) 2016/427 of 10 March 2016 Amending Regulation (EC) No 692/2008 as Regards Emissions from light Passenger and Commercial Vehicles (Euro 6). Available online: https://eur-lex.europa.eu/eli/reg/ 2016/427/oj (accessed on 29 December 2020).

16. Belgiorno, G.; Boscolo, A.; Dileo, G.; Numidi, F.; Pesce, F.C.; Vassallo, A.; Ianniello, R.; Beatrice, C.; Di Blasio, G. Experimental Study of Additive-Manufacturing-Enabled Innovative Diesel Combustion Bowl Features for Achieving Ultra-Low Emissions and High Efficiency; No. 2020-37-0003; SAE Technical Paper: Warrendale, PA, USA, 2020.

17. Di Blasio, G.; Beatrice, C.; Ianniello, R.; Pesce, F.C.; Vassallo, A.; Belgiorno, G.; Avolio, G. Balancing hydraulic flow and fuel injection parameters for low-emission and high-efficiency automotive diesel engines. SAE Int. J. Adv. Curr. Pract. Mobil. 2019, 2019, 638-652.

18. Lee, T.; Park, J.; Kwon, S.; Lee, J.; Kim, J. Variability in operation-based NOx emission factors with different test routes, and its effects on the real-driving emissions of light diesel vehicles. Sci. Total Environ. 2013, 461, 377-385. [CrossRef] [PubMed]

19. Ko, S.; Park, J.; Kim, H.; Kang, G.; Lee, J.C.; Kim, J.; Lee, J.T. NOx emissions from Euro 5 and Euro 6 heavy-duty diesel vehicles under real driving conditions. Energies 2020, 13, 218. [CrossRef]

20. Korean MLIT, Ministry of Land, Infrastructure and Transport. Total Registered Motor Vehicles 2018. Available online: http: / / stat.molit.go.kr (accessed on 29 December 2020).

21. Tutuianu, M.; Bonnel, P.; Ciuffo, B.; Haniu, T.; Ichikawa, N.; Marotta, A.; Pavlovic, J.; Steven, H. Development of the World-wide harmonized Light duty Test Cycle (WLTC) and a possible pathway for its introduction in the European legislation. Transp. Res. Part D Transp. Environ. 2015, 40, 61-75. [CrossRef]

22. National Institute of Environmental Research (NIER). National Inventories for Air Pollutants from Transportation Sector. Part 1: Development of Laboratory Driving Cycles to Derive Average Speed Based Emissions Models for On-Road Vehicles; NIER: Incheon, Korea, 2001.

23. United Nations Regulation No. 83: Revision 5. Uniform Provisions Concerning the Approval of Vehicles with Regard to the Emission of Pollutants according to Engine Fuel Requirements. Available online: http:/ /www.unece.org/fileadmin/DAM/ trans/main/wp29/wp29regs/r083r4e.pdf (accessed on 29 December 2020).

24. Netherlands Vehicle Authority (RDW). Emission Test Programme: Results of the Follow-Up Investigation into the Presence of Unauthorized Defeat Devices. Available online: https://www.rdw.nl/-/media/rdw/rdw/pdf/sitecollectiondocuments/over$\mathrm{rdw} /$ rapporten/rdw-emission-test-programme-english.pdf (accessed on 29 December 2020).

25. Ramos, A.; Munoz, J.; Andres, F.; Armas, O. NOx emissions from diesel light duty vehicle tested under NEDC and real-word driving conditions. Transp. Res. Part D Transp. Environ. 2018, 63, 37-48. [CrossRef]

26. Weiss, M.; Bonnel, P.; Kuhlwein, J.; Provenza, A.; Lambrecht, U.; Alessandrini, S.; Carriero, M.; Colombo, R.; Forni, F.; Lanappe, G.; et al. Will Euro 6 reduce the NOx emissions of new diesel cars?-Insights from on-road tests with Portable Emissions Measurement Systems (PEMS). Atmos. Environ. 2012, 62, 657-665. [CrossRef]

27. Matsumoto, S.I. Recent advances in automobile exhaust catalysts. Catal. Today 2004, 90, 183-190. [CrossRef]

28. Kadijk, G.; Ligterink, N.; van Mensch, P.; Smokers, R. NOx Emissions of Euro 5 and Euro 6 Diesel Passenger Cars-Test Results in the Lab and on the Road; TNO: Delft, The Netherlands; Available online: https: / / www.automobielmanagement.nl/download/TNO2016-R10083_RW-NOx_diesel-passenger-cars_final.pdf (accessed on 29 December 2020).

29. Ntziachristos, L.; Samaras, Z. Sectoral Guidance 1.A.3.b Road Transport. EMEP/EEA Air Pollutant Emission Inventory Guidebook 2016; European Environmental Agency: Copenhagen, Demark. Available online: https:/ /www.eea.europa.eu/publications/emep-eeaguidebook-2016/part-b-sectoral-guidance-chapters/1-energy/1-a-combustion/1-a-3-b-i-1/view (accessed on 29 December 2020). 